\title{
Reconstruction of Scrotal and Perineal Defects in Fournier's Gangrene
}

\author{
Hakim Chabak*, Amine Rafik, Mohammed Ezzoubi, Mounia Diouri, Naïma Bahechar, \\ Abdessamad Chlihi \\ National Center of Burns and Plastic Surgery, Ibn Rochd University Hospital, Casablanca, Morocco \\ Email:
}

Received 3 May 2015; accepted 27 June 2015; published 30 June 2015

Copyright @ 2015 by authors and Scientific Research Publishing Inc.

This work is licensed under the Creative Commons Attribution International License (CC BY). http://creativecommons.org/licenses/by/4.0/

c) (i) Open Access

\begin{abstract}
Fournier's gangrene described in 1883 by Jean Alfred Fournier, still poses ethiopathogenic, evolutive and therapeutic problems. This is a therapeutic emergency; early diagnosis, medical and surgical treatments contribute to reducing mortality rate. Tissue defect engendered by infection and/or by its excision requires morphological and functional reconstruction. The choice of the reconstruction technique depends on several parameters: early or delayed coverage, the size of the defect, the local capital skin and the patient's general condition. Through this study involving 95 cases of scrotal and perineal gangrene treated at the National Center of Burns and Plastic Surgery of Ibn Rochd University Hospital of Casablanca over a period of 10 years (2004-2014), we report our approach in the surgical management of defect secondary to Fournier's gangrene.
\end{abstract}

\section{Keywords}

Fournier's Gangrene, Scrotal and Perineal, Flap, Scrotal Advancement

\section{Introduction}

Since its first description by Jean Alfred Fournier in 1883 under the title of fulminating gangrene of the penis [1], Fournier's gangrene (FG) which is defined as an acute dermo-hypodermic bacterial infection necrotizing with fast and unpredictable evolution to necrosis of scrotal and perineal tissues, still poses etiopathogenic, evolutive and therapeutic problems. Whether primitive or secondary to uro-genital, colorectal or perineal infection, Fournier's gangrene remains a serious affection by its local, regional and general complications. The mortality rate varies between $20 \%$ and $80 \%$. It is a therapeutic emergency; early diagnosis and appropriate treatment contribute to reducing mortality [2]. The defect engendered by infection and/or its excision requires surgical recon-

${ }^{*}$ Corresponding author.

How to cite this paper: Chabak, H., Rafik, A., Ezzoubi, M., Diouri, M., Bahechar, N. and Chlihi, A. (2015) Reconstruction of Scrotal and Perineal Defects in Fournier's Gangrene. Modern Plastic Surgery, 5, 23-27.

http://dx.doi.org/10.4236/mps.2015.53005 
struction that aims to repair both morphology and function. Through this work involving 95 cases of perineal scrotal gangrene treated at the National Center of Burns and Plastic Surgery in Ibn Rochd University Hospital of Casablanca, we report our experience and approach in the surgical management of perineal and scrotal defects secondary to Fournier's gangrene. Criteria that follow.

\section{Materials and Methods}

Our study is retrospective descriptive over a period of 10 years (2000-2014) involving 95 patients, performed at the National center of burns and plastic surgery of IBN Rochd University Hospital of Casablanca. The Data were collected from medical records of patients and we analyzed the indications and results in patients followed in our center. The study included all patients with Fournier's gangrene who received a multidisciplinary treatment combining intensive care measures with triple antibiotherapy (aminosid-Imidazole-Amoxicillin-Clavulanic AC), an initial surgical treatment and a time of early or delayed reconstruction. The results of the reconstruction, according to the technique used, the location and extension of the defect were evaluated by functional and aesthetic objective criteria.

\section{Results}

All patients underwent surgical debridement of necrotic soft tissue of the scrotum and/or perineum. 72 patients (76\% of the cases) required one or more iterative debridement. The average area of the defect caused by the debridement was $105 \mathrm{~cm}^{2}$. Our surgical indications summarized in Table 1 had emerged from early or delayed character of coverage, the size of the defect and the local tissue capital; When early reconstruction was indicated in 23 patients (a quarter of our patients), the myocutaneous gracilis flap was privileged. For patients who received delayed reconstruction, secondary healing was reserved for small defects or in patients with high anesthetic risk patients (10 cases; $10.5 \%$ of patients); a scrotal advancement and secondary suture were possible in 24 patients in whom the size of the defect did not exceed $50 \%$ of the surface of the scrotum; When the defect was extended to the scrotum, perineum and/or abdominal wall, reconstruction using skin graft was performed in 16 patients. 16 patients (17\% of cases) underwent a reconstruction by internal fascicutaneous thigh flaps when the defect exceeded $50 \%$ of the scrotum and extended to perineum without reaching the root of the thigh nor abdomen, and 7 patients were reconstructed by myocutaneous gracilis flap for uneven defect increasing the risk of formation of a dead space. We noticed simple operative follow-ups in more than $80 \%$ of cases and minor postoperative complications such as suture release (5 cases), partial flap necrosis ( 3 cases) and partial lysis of the skin graft ( 2 cases) which were managed by secondary healing. Table 2 sums up postoperative complications met in our series.

\section{Discussion}

The management of perineal and scrotal gangrene combines intensive cares measures (management of hydroelectrolytic troubles, management of renal, hepatic and respiratory failure) a triple-antibiotherapy probabilistic at start and then adapted to the results of bacteriological samplings and surgical debridement in emergency combined or not digestive derivation depending on the localisation and an urinary catheter or cystostomy in case

Table 1. Reconstruction techniques of scrotal and perineal defects in Fournier's gangrene in our study.

\begin{tabular}{|c|c|c|c|}
\hline Reconstruction & Technique & Case & $\%$ \\
\hline \multirow[t]{3}{*}{ Early } & Musculo-cutaneous flap (Gracilis) & 23 & $24.2 \%$ \\
\hline & Secondary healing & 10 & $10.5 \%$ \\
\hline & Avancement scrotal & 24 & $25.2 \%$ \\
\hline \multirow[t]{3}{*}{ Delayed } & Skin graft & 16 & $16.85 \%$ \\
\hline & Fascio-cutaneous thigh flap & 16 & $16.85 \%$ \\
\hline & Musculo-cutaneous flap (Gracilis) & 6 & $6.3 \%$ \\
\hline
\end{tabular}


Table 2. Postoperative complications in our study.

\begin{tabular}{ccc}
\hline Suites & Case & $\%$ \\
\hline Simples & 83 & $87.4 \%$ \\
Infection and suture release & 5 & $5.3 \%$ \\
Hematoma & 3 & $3.14 \%$ \\
Flap partial necrosis & 2 & $2.1 \%$ \\
Partial lysis skin graft & 2 & $2.1 \%$ \\
\hline
\end{tabular}

of urethral affection [3]. The initial surgical debridement consists of a wide excision of all necrotic tissue going through healthy tissue in the periphery and in depth.

We performed a wide excision and early reconstruction by a musculocutaneous flap (gracilis) in $24 \%$ of our patients. In fact, when the patient's general condition, quality of initial debridement and locoregional possibilities (slightly extended gangrene) allow it, early coverage was carried out. A musculocutaneous flap called for. We think that this approach has several advantages compared to conventional approaches; on one hand, the muscle adapts itself better to surfaces which reduces the rate of postoperative complications (seroma, hematoma), and it also limits the extension of the septic process by bringing trophic muscular tissue well vascularized, more resistant to infection and anabling the diffusion of antibiotics. On the other hand, early reconstruction reduces the healing delay and duration of wound care; this shortens the stay in hospital and improves the quality of life of the patients.

In other situations, which represent the majority (insufficient initial debridement, hemodynamic instability) reconstruction is postposed. We will use iterative debridement (second looks) for better control of the infection. Regular dressings are made to speed up debridement of necrotic tissue at start and favouring granulation and then cicatrisation. Negative pressure dressings (VAC) have their indication and would be efficient in the treatment of slightly extended Fournier gangrene. Likewise, Hyperbar Oxygen (HBO) can be discussed for its prohealing action and anti-infections action against anaerobic bacteria such as Clostridium [4]. We do not dispose HBO or VAC and they were not practiced in any patient in our series. The coverage of the defect called for different techniques of plastic surgery: secondary healing, advancement flap, thin skin graft, full thickness skin graft, local or regional flap. The choice of technique will depend on the size of the defect and the local tissue capital. Contrarily to testicular burying, Repair would be both morphological and functional aiming at not only to recreate a néoscrotum but to reduce the risk of sterility secondary to traumas to which the testicles are submitted during movements [5] [6] (Figure 1).

Secondary healing is a simple means favored by the vascular richness of the scrotum and by its regenerative capacity. It should be reserved to small size defect or in patients with high anesthetic risk due to the extended time for healing, the risk of secondary infection and retractile phenomena often leading to scrotal deformation. The scrotal advancement flap benefits of the extensibility of the scrotum. The unaffected scrotal skin will be advanced to cover the defect. This applies to isolated small to moderate scrotal defect losses $\leq 50 \%$ [7]. The skin graft is a safe means of coverage that is technically easy to implement provided that the tunica vaginalis is preserved [8]. It allows a rapid coverage of wide defect extending to the abdominal wall, the sidewalls or thighs. This technique would be less providing of sterility secondary to the increase of testicular temperature. However, it has some drawbacks: the graft is sometimes difficult to apply in uneven area and the technique remains purveyor of retractions and ulcerations. It is therefore preferable to graft the testicles and perineum in total skin that has less tendency to retract. The fasciocutaneous flaps have the advantage compared to the skin graft to cover large perineal and scrotal defect without tendency to retraction. The pudendal and anterolateral thigh flaps [9]-[12] and Mc gregor flap [13] are interesting alternatives according to the defect localisation. They give a satisfactory functional and cosmetic result with less donor site morbidity compared with a musculocutaneous flap. When the perineal and scrotal defect is deep and uneven a muscular transfer is often necessary. It allows defect filling without dead space. However, its thickness is sometimes the cause of a cosmetic disgrace. The musculocutaneous flap of gracilis muscle is the most used [14] [15], the abdominal rectus flap has also been described in this indication [16]. 


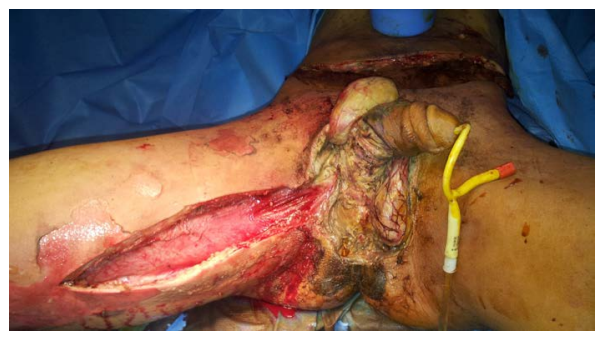

(a)

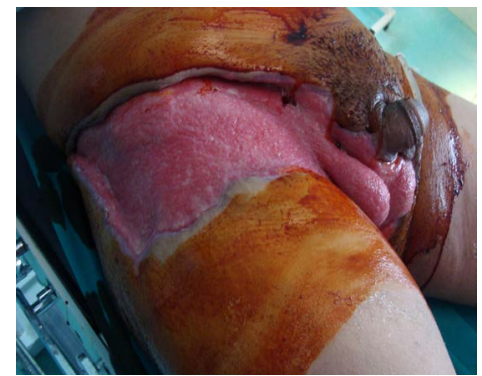

(b)

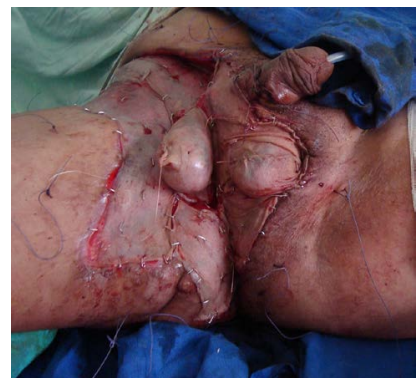

(c)

Figure 1. (a) Fournier gangrene with extension to the right thigh and abdomen that required to discharge incision; (b) Loss of inguinal and scrotal substance budding post gangrene Fournier; (c) Skin graft coverage with semi-thick skin harvested from the ipsilateral thigh.

\section{Conclusion}

The périnéoscrotale gangrene is a serious condition often involving the vital prognosis of the patients. Its prognosis depends on the earliness and quality of initial management. The repair aim is to obtain coverage that is both functional and aesthetic. The choice of technique depends on several parameters: early or delayed coverage, the size of the defect, the local capital skin, general condition of the patient and the surgeon's practices. A quick and good coverage mainly using musculocutaneous flap, helps to improve the quality of life of patients and reduce the cost of care.

\section{Disclosures}

The author has no financial or commercial interest to declare in relation to the content of this article.

\section{Authors and Affiliations}

Dr. Hakim CHABBAK (1): Bibliographic search.

Dr. Amine RAFIK (2): Corresponding author.

Pr. Mohammed EZZOUBI (3): Scientific support.

Pr. Mounia DIOURI (4): Scientific support.

Pr. Naïma BAHECHAR (5): Scientific support.

Pr. Abdessamad CHLIHI (6): Head master of national center of burns and plastic surgery: Morocco.

\section{References}

[1] Eke, N. (2000) Fournier’s Gangrene: A Review of 1726 Cases. British Journal of Surgery, 87, 718-728. http://dx.doi.org/10.1046/j.1365-2168.2000.01497.x

[2] Sorensen, M.D., Krieger, J.N., Rivara, F.P., Klein, M.B. and Wessells, H. (2009) Fournier’s Gangrene: Management and Mortality Predictors in a Population Based Study. Journal of Urology, 182, 2742-2747. http://dx.doi.org/10.1016/j.juro.2009.08.050

[3] Ozkan, O.F., et al. (2014) Fournier’s Gangrene Current Approaches. International Wound Journal. http://dx.doi.org/10.1111/iwj.12357 
[4] Lipsker, A., et al. (2014) Gangrène de Fournier: Prise en chargechirurgicale. Progrès FMC, 24, F80-F85. http://dx.doi.org/10.1016/j.fpurol.2014.06.001

[5] Boukind, H., Ezzoubi, M. and Chafiki, N. (1995) La reconstruction scrotale après cellulite nécrosante du périnée et des organes génitaux externes: A propos de 21 cas. Annales d'Urologie, 9, 309-312.

[6] Czymek, R., Kujath, P., Bruch, H.P., Pfeiffer, D., Nebrig, M., Seehofer, D. and Guckelberger, O. (2013) Treatment, Outcome and Quality of Life after Fournier’s Gangrene: A Multicenter Study. Colorectal Disease, 15, 1529-1536. http://dx.doi.org/10.1111/codi.12396

[7] Chen, S.Y., Fu, J.P., Chen, T.M. and Chen, S.G. (2011) Reconstruction of Scrotal and Perineal Defects in Fournier's Gangrene. Journal of Plastic, Reconstructive Aesthetic Surgery, 64, 528-534. http://dx.doi.org/10.1016/j.bjps.2010.07.018

[8] Maguina, P., Palmieri, T.L. and Greenhalgh, D.G. (2003) Split Thickness Skin Grafting for Recreation of the Scrotum Following Fournier's Gangrene. Burns, 29, 857-862. http://dx.doi.org/10.1016/j.burns.2003.07.001

[9] Hanasono, M.M., Skoracki, R.J. and Yu, P. (2010) A Prospective Study of Donor Site Morbidity after Anterolateral Thigh Fasciocutaneous and Myocutaneous Free Flap Harvest in 220 Patients. Plastic and Reconstructive Surgery, 125, 209-214. http://dx.doi.org/10.1097/PRS.0b013e3181c495ed

[10] Karsidag, S., Akcal, A., Sirvan, S.S., Guney, S. and Ugurlu, K. (2011) Perineoscrotal Reconstruction Using a Medial Circumflex Femoral Artery Perforator Flap. Microsurgery, 31, 116-121. http://dx.doi.org/10.1002/micr.20839

[11] Mauro, V. (2011) Fasciocutaneous Flap of the Inner Thigh for Scrotal Reconstruction in Fournier Syndrome. Revista Brasileira de Cirurgia Plástica, 26, 707-709. http://dx.doi.org/10.1590/S1983-51752011000400030

[12] Yang, J., Ko, S.H., Oh, S.J. and Jung, S.W. (2013) Reconstruction of a Perineoscrotal Defect Using Bilateral Medial Thigh Fasciocutaneous. Archives of Plastic Surgery, 40, 72-74. http://dx.doi.org/10.5999/aps.2013.40.1.72

[13] Cannistra, C., Kirsch-Noir, F., Delmas, V., Marmuse, J.-P. and Boccon-Gibod, L. (2003) La reconstruction du scrotum après gangrène de Fournier par lambeau inguinal. Progrès en Urologie, 13, 703-706.

[14] Crane, C., Cornejo, A., Lyons, R. and Alter, G.J. (2013) Urethral Reconstruction Using a Prefabricated Pedicled Gracilis Flap. Annals of Plastic Surgery, 70, 691-693. http://dx.doi.org/10.1097/SAP.0b013e3182414843

[15] Lee, S.H., Rah, D.K. and Lee, W. (2012) Penoscrotal Reconstruction with Gracilis Muscle Flap and Internal Pudendal Artery Perforator Flap Transposition. Journal of Urology, 79, 1390-1394. http://dx.doi.org/10.1016/j.urology.2012.01.073

[16] Yanagi, M., Nishimura, T., Kondo, Y., Yamazaki, K., Sakai, S., Ishii, N., Kojo, K. and Hosoda, K. (2011) A Case of Fournier's Gangrene Reconstructed Using a Rectus Abdominis Muscle Flap. Nihon Hinyokika Gakkai Zasshi, 102, 649-654. http://dx.doi.org/10.5980/jpnjurol.102.649 